\title{
Family Physicians Delivering Babies? It's Time to Decide
}

Kirsten Winnie, MD; John Saultz, MD

(Fam Med. 2021;53(5):325-7.)

doi: 10.22454/FamMed.2021.782821

W e have been debating the role of maternity care in family medicine since the earliest days of our specialty. ${ }^{1-5}$ Arguments are made. Compromises are reached. Rarely have we taken time to examine the consequences of our choices. In 2014, the Accreditation Council for Graduate Medical Education (ACGME) updated the family medicine program requirements by removing minimum total and continuity delivery targets. Prior to this change, family medicine residents were required to perform a minimum of 40 vaginal deliveries before graduation with at least 10 of them taking place with continuity patients. ${ }^{6,7}$ This target was hard for many programs to reach and not all graduates used the skills resulting from their training, so the requirement was removed. In this issue of Family Medicine, Julia Fashner, MD, $\mathrm{MPH}$, and colleagues report some of the results arising from this decision. ${ }^{8}$ Family medicine residents now deliver fewer babies, and their programs make maternity care less of a priority. Of greater concern, the percentage of family physicians in practice providing maternity care has declined as well. ${ }^{3,6}$ Some might question whether these two things are related, but isn't that always the case when examining outcomes evidence? The sole note of optimism in this paper is that programs with strong maternity care priorities at baseline are largely unaffected. But what does it mean that a minority of our programs now shoulder the responsibility?

Family physicians' maternity care skills are critical to the health of rural and underserved communities. ${ }^{9-12}$ Family-centered maternity care is protective against burnout ${ }^{13-15}$ and maintains youth in our practices. ${ }^{16}$ More importantly, maternity care is deeply interwoven with primary care for women. Because reproductive health concerns are a common entry point for women in primary care, caring for women means caring for their reproductive health. ${ }^{17}$ Even internists agree that common women's health concerns should not be referred routinely to obstetricians. ${ }^{18}$ Many would also agree that pregnancy diagnosis and prenatal care are also part of primary care for women. But does it make sense to provide women's health and prenatal care when we do not perform deliveries? Why would women choose to receive prenatal care from someone who will be absent from their deliveries? So we agree as a specialty that we don't want to withdraw entirely from women's care, but we cannot agree on which services should be included in our basic scope of care. While we debate the issue, family physicians who provide maternity care have become an endangered species. ${ }^{3}$ If we don't protect this practice, soon it won't remain available to our specialty. Is this really what we want to happen? Is this who we want to be?

With another revision process currently underway for ACGME family medicine program requirements, ${ }^{19}$ we will once again choose the core content of our residency programs. Shall we recommit to the ideal of universally training full-scope family physicians? Or is that naïve and unrealistic? If we blame our declining numbers of maternity care providers on the

From the David Grant USAF Medical Center, Fairfield, CA (Dr Winnie); and Oregon Health and Science University, Department of Family Medicine (Dr Saultz). 
2014 change, we might also credit it for allowing substantial growth in the number of approved residencies. How many of our over 700 residencies would lose accreditation if we returned to the previous standard? Perhaps we should accept that only a minority of us will provide maternity care and move maternity care training into fellowships, allowing us to focus the training on those who will actually use it. Using a fellowship model would also allow programs that don't need family physicians to practice maternity care locally to focus curricula elsewhere. Negotiating maternity privileges and expanding obstetric patient volume takes energy and resources; depending on maternity care fellowships instead is an appealing solution. But is it the right solution? We have resisted narrowing our core scope for good reason., ${ }^{2,19-21}$ Some family physicians already focus their practices narrowly on maternal-child health. Perhaps this is a consequence of entering fellowships directly after residency because maternity fellowships do not routinely allow fellows to maintain and build on nonmaternity care skills, making it harder to return to the full scope later.

Let's consider other options. We could decide to train every resident to perform basic maternity care and accept that some residencies will close as a result. Conversely, we could decide that maternity care does not belong in the core residency, only in maternity care fellowships, and deal with the consequences. But the same communities that depend on us for maternity care also depend on us for hospital care and ER coverage, so another option is to move maternity care training into comprehensive rural medicine fellowships. We could always continue our current tiered training model, but Fashner and colleagues have shown us that this model has not worked very well.

Perhaps this is a time to consider creative, bold solutions instead of the same tired tactics we've used for 50 years. We could expand to a 4-year residency model to increase the supply of physicians ready to practice comprehensive family medicine including maternity care upon graduation. ${ }^{23}$ We could require a period of apprenticeship in full-scope practices including maternity care for 1-3 years after residency, but before board certification. Graduates would then decide after this apprenticeship what their scope of practice will be. Finally, we could change our focus to continuity care with families. Family physicians do family-centered maternity care, which has unique strengths adapting with the life cycle of women and their families. We care for women for years after their deliveries; family-centered maternity care is part of our continuity relationships with families. We also care for the babies as they grow up, and for their fathers and grandparents. Perhaps we might create residency tracks focusing on young and aging families? Those choosing to focus on young families would learn to care for children, maternity care, and acute complaints while those focusing on aging families could focus on chronic conditions and geriatrics. Practices could recruit from both pools, and physicians could learn from one another, adapting their practices as they progress through their careers.

Before we make these decisions, a critical question must be considered: what model of family medicine will appeal to current and future medical students? Perhaps potential family physicians choose other specialties not because the idea of full-scope family medicine is unappealing, but because the reality of adult, ambulatory primary care practice is. ${ }^{24-}$ ${ }^{26}$ Recent data suggest that many residency graduates desire to continue maternity care, but cannot find a supportive practice. ${ }^{27-29}$ Are we really sending a message to students that it is achievable to be broadly competent, to care for patients from cradle to grave, and to do so in a practice that is fulfilling, not defeating? Bridging this gap is crucial—not everyone can work in the rare settings where maternity care is currently an option. So it needs to be possible everywhere. Expanding opportunities for family physicians to practice maternity care is likely to be a virtuous cycle, allowing us to rescue this endangered species from the brink.

In any case, inaction, timidity, and delay are self-defeating. While avoiding hard choices might seem like a good idea in the short run, indecisive compromise led us to where we are today. The events of the past year, including managing the COVID-19 pandemic, combating systemic racism, and addressing climate change evoke this lesson: denial is a poor strategy. Medical students and the public should see our choices as bold, forward-thinking, and focused on the public interest. Our nation will never have the primary care workforce it needs if we don't make this work rewarding for those who do it. There is probably more than one way to achieve this goal. The enemy is equivocation and internal dissention. It's time to get on with it. 
DISCLAIMER: The views expressed in this article represent those of the authors and do not reflect the official position of the US Air Force, Uniformed Services University of the Health Sciences, the US Government, or Department of Defense at large.

\section{References}

1. Nesbitt TS. Obstetrics in family medicine: can it survive? J Am Board Fam Pract. 2002;15(1):77-79.

2. Chen FM. Maternity care is essential to family medicine. Fam Med. 2020;52(2):155. doi:10.22454/FamMed.2020.394821

3. Young RA, Sundermeyer RL. Family medicine and obstetrics: let's stop pretending. J Am Board Fam Med. 2018;31(3):328331. doi:10.3122/jabfm.2018.03.180087

4. Larimore WL, Reynolds JL. Family practice maternity care in America: ruminations on reproducing an endangered species-family physicians who deliver babies. J Am Board Fam Pract. 1994;7(6):478-488.

5. Stewart WL. Clinical implications of the national study of the content of family practice. J Fam Pract. 1982;15(4):723-725.

6. Magee SR, Eidson-Ton WS, Leeman L, et al. Family medicine maternity care call to action: moving toward national standards for training and competency assessment. Fam Med. 2017;49(3):211-217.

7. Accreditation Council for Graduate Medical Education ACGME program requirements for graduate medical education in family medicine. https://acgme.org/Portals/0/ PFAssets/ProgramRequirements/120_FamilyMedicine_2019. pdf?ver=2019-06-13-073936-407. Published 2019. Accessed March 9, 2020

8. Fashner J, Cavanaugh C, Eden A. Comparison of maternity care training in family medicine residencies 2013 \& 2019: a CERA program directors' survey. Fam Med. 2021;53(6);331337.

9. Tong ST, Eden AR, Morgan ZJ, Bazemore AW, Peterson LE. The essential role of family physicians in providing cesarean sections in rural communities. J Am Board Fam Med. 2021;34(1):10-11. doi:10.3122/jabfm.2021.01.200132

10. Kozhimannil KB, Hung P, Henning-Smith C, Casey MM, Prasad S. Association between loss of hospital-based obstetric services and birth outcomes in rural counties in the United States. JAMA. 2018;319(12):1239-1247. doi:10.1001/ jama.2018.1830

11. Waits JB, Smith L, Hurst D. Effect of access to obstetrical care in rural Alabama on perinatal, neonatal, and infant outcomes: 2003-2017. Ann Fam Med. 2020;18(5):446-451. doi:10.1370/afm. 2580

12. Kozhimannil KB, Frakt A. Rural America's disappearing maternity care. The Washington Post. https://www.washingtonpost.com/opinions/rural-americas-disappearing-maternity-car e/2017/11/08/11a664d6-97e6-11e7-b569-3360011663b4 story. html. Published November 8, 2017. Accessed March 20, 2021.

13. Weidner AKH, Phillips RL Jr, Fang B, Peterson LE. Burnout and scope of practice in new family physicians. Ann Fam Med. 2018;16(3):200-205. doi:10.1370/afm.2221

14. Kadia K. In response to "The impact of pacticing obstetrics on burnout among early-career family physicians". Fam Med. 2021;53(2):157. doi:10.22454/FamMed.2021.863553
15. Ly E. A day in the life of a rural generalist. On the Wards. https://onthewards.org/a-day-in-the-life-of-a-rural-generalist/. Published March 31, 2019. Accessed February 9, 2021

16. Nesbitt TS, Kahn NB, Tanji JL, Scherger JE. Factors influencing family physicians to continue providing obstetric care. West J Med. 1992;157(1):44-47.

17. Martinez G, Chandra A, Febo-Vazquez I, Mosher W. Use of family planning and related medical services among women aged 15-44 in the United States: National Survey of Family Growth, 2006-2010. Natl Health Stat Report. 2013;(68):1-16, 20

18. Daniel H, Erickson SM, Bornstein SS; Health and Public Policy Committee of the American College of Physicians. Women's health policy in the United States: an American College of Physicians position paper. Ann Intern Med. 2018;168(12):874-875. doi:10.7326/M17-3344

19. Newton WP, Magill M, Biggs W, et al. Re-envisioning family medicine residencies: the end in mind. J Am Board Fam Med. 2021;34(1):246-248. doi:10.3122/jabfm.2021.01.200604

20. Saultz J. Experience matters. Fam Med. 2021;53(1):7-8. doi:10.22454/FamMed.2021.572008

21. Saultz J. Stewardship. Fam Med. 2019;51(5):381-382. doi:10.22454/FamMed.2019.417285

22. Saultz J. Residency education at a crossroads. Fam Med. 2017;49(5):337-338. doi:10.22454/FamMed.2018.361195

23. Eiff MP, Hollander-Rodriguez J, Skariah J, et al. Scope of practice among recent family medicine residency graduates. Fam Med. 2017;49(8):607-617.

24. Kardonsky K, Evans DV, Erickson J, Kost A. Impact of a targeted rural and underserved track on medical student match into family medicine and other needed workforce specialties. Fam Med. 2021;53(2):111-117. doi:10.22454/ FamMed.2021.351484

25. Chen DYO. O doctor, where art thou? Why fewer students pursue internal medicine. Virtual Mentor. 2009;11(5):378382. doi:10.1001/virtualmentor.2009.11.5.jdsc1-0905

26. Creighton S. "Why Waste a Medical Education on Primary Care?" https://opmed.doximity.com/articles/why-waste-amedical-education-on-primary-care-edc497ed-fc19-4ddf-be32a86533975a21. Published June 12, 2013. Accessed February 9, 2021.

27. Barreto TW, Eden AR, Petterson S, Bazemore AW, Peterson LE. Intention versus reality: family medicine residency graduates' intention to practice obstetrics. J Am Board Fam Med. 2017;30(4):405-406. doi:10.3122/jabfm.2017.04.170120

28. Eden AR, Barreto T, Hansen ER. Experiences of new family physicians finding jobs with obstetrical care in the USA. Fam Med Community Health. 2019;7(3):e000063. doi:10.1136/ fmch-2018-000063

29. Barreto TW, Eden AR, Hansen ER, Peterson LE. Barriers faced by family medicine graduates interested in performing obstetric deliveries. J Am Board Fam Med. 2018;31(3):332333. doi:10.3122/jabfm.2018.03.170427 